\title{
Social Pathology of Dementia
}

\author{
Mario D Garrett* \\ Professor of Gerontology, San Diego State University, USA
}

*Corresponding author: Mario D Garrett, Professor of Gerontology, San Diego

State University, USA

\section{Short Communication}

When Alois Alzheimer first discussed his findings about plaques and tangles in dementia at the 1906-7 Psychiatric Convention of the South West German Society in Tubingen there was no discussion and no interest shown. His first attempt to publish the findings was rejected. It was already known at the time dementia results in the biological markers of plaques and tangles. It was Emil Kraepelin, Alois Alzheimer's supervisor, that pushed for the publication of these observations and later adopted Alzheimer's eponym for the disease. But this was all about political and not science. The argument was that although these biological markers were common, it was not common among younger people, and hence the need for a new disease. It was an ageist argument where a disease is valid because it afflicts younger people. However, even this distinction was eliminated. In 1976 Richard Katzman combined senile ("old age") dementia with Alzheimer's disease. He did this not to reclaim science but to gain a larger constituency for Alzheimer's disease in order to promote the mission of the recently established United States National Institute on Aging (NIA). Again, politics won above science. But this confabulation resulted in Alzheimer's disease research becoming confused and lacking theory. The resulting confusion has recently led the NIA to start promoting the diagnoses of Alzheimer's disease based on biological markers and not on clinical diagnosis, For the first time in the history of medicine, there is a push to diagnose a clinical disease based on biology while ignoring clinical evidence. This is the holy grail of psychiatry. However, evidence contradicts NIA's aspiration. These biological markers-colloquially referred to as plaques and tangles - are not consistently correlated to Alzheimer's disease or dementia. Half of clinically diagnosed oldest-old with dementia have insufficient neuropathology to account for their dementia, while thirty to fifty percent of older adults without dementia meet the neuropathological criteria for Alzheimer's disease, , , , , , . Among older people, the correlation between Alzheimer's disease neuropathology and its clinical expression declines. It is disturbing that we have known this fallacy for more than a century. Yet we continue to promote this simplistic cause of dementia and the only way to change this theoretical rigidity is to think more creatively outside of the political (and funding) interests.

A recent review identified close to a hundred different documented causes of dementia. These causes are so broad that researchers suggest that dementia might be a biological strategy. Because the brain is incredibly complex, it attracts, isolates, and insulates a myriad of biological attacks. Suggesting that this short-term strategy leads to long-term liability for dementia. But even these broad biological causes do not explain all the cases of dementia. Another process must be influencing the development of dementia.

One of the avenues that might explain this process is psychology, especially by looking at how learning affects memory in older age. Older adults, because of their ample experience, have developed a complex and reliant model of their environment-an isomorphic representation. When it comes to problem solving, older adults are more likely to rely on this constancy in favor of looking at the current environment. This experience based on past successes and failures, determines how the present is addressed and "the 
capacity of older adults to draw on accumulated experience in socioemotional realms to solve problems successfully." Their isomorphic representation becomes self-reliant, needing little input from outside. Older adults become so efficient engaging in regular activities (e.g., reading, driving, communicating, talking, and anticipating events) that divergence away from their routine becomes difficult. Most older adults enter a tunnel vision that involves more control and inhibition, especially as found with eidetic imagery, Older participants spend more scan time on a small area in an image whereas younger participants scanned the images more evenly. Becoming aware that most answers can be found in past experiences, the brain reduces learning from the environment. As with London taxi drivers where middle-aged men learned directions to over 60,000 streets and 100,000 places of interest in the city, there is a price to becoming proficient in one task, it restricts learning novel tasks. All of this happens unconsciously, without awareness. Although retrieving information from our past is very efficient, it eventually subverts the role of memory. Memory's role is not just to recall past events, it is to recall past event so that we use these experiences as a lesson for the present, to better anticipate our future. We should ask not what memory is, but what memory is for.

Unconsciously, a tipping point is reached where the brain changes from looking for answers from the outside to looking for answers from our experiences. The self-reliance on our isomorphic representation ensures that the outside world becomes increasingly ignored and discounted. As we reduce learning, we automatically stop using memory as it was intended for, relegating memory as increasingly redundant. This is the social pathology of dementia. Not that dementia affects memory, but that memory promotes dementia.

As a result, we start noticing deficits in the first stage of memory-short-term memory. Problems in this early conduit of memory causes a cascade of bigger memory problems in time. For example, in the Nun Study that looked at language use 50 years previous on some 700 retired midwestern nuns, found that all the novices who wrote autobiographical essays in very simple sentences died with symptoms of Alzheimer's, but none of those whose prose style was more complex succumbed to the disease. Even in their 20s, problems with short-term memory consequently had devastating clinical repercussions in their 70 s even when living conditions were the same for the nuns. When such problems become more obvious, we try to rationalize these memory lapses and we find a ready-made stereotype: dementia. By assigning a term we effectively create a tipping point where we start to unconsciously substantiate this term. We do this through hundreds of different biases. An example of such biases includes "confirmatory bias" and "inattentive/change blindness." We massage our memory to fit a narrative. One study measured how well well-prepared students were for an exam and then two-weeks later, after the exam result, they were asked the same questions again. The study found convergence, whereby those students who received good grades reported more time studying, while those students that had a bad grade reported less time studying than they had reported earlier. In another study asked participants to be attentive to the number of times a group of three players (out of two groups) pass a ball between themselves. While counting this activity, a person in a gorilla costume enters and then leaves the background. Around half of people will simply not "see" the gorilla. We are unlikely to see events that do not conform to our task at hand. As with dementia, we only see (and other only highlight) problems with our memory, even when there is no biological evidence. These perceptual biases ensure that any evidence that negates the subjective evaluation of memory loss is ignored. We only perceive events that support our judgement. Once we make these judgements it is difficult, if not impossible, to reverse-even if there is evidence to the contrary. This is difficult to understand without psychology, because we realize that what is important is that we need to make a coherent story. Whatever happens to us, we need to ensure that there is coherence. People who are told that their memory is bad will try and find a tipping point, in most cases, they will create one. They will recall that their memory was better before, when it was not. But such judgement rationalizes their experiences that "something aberrant happened" and that something can only be dementia. These are all powerful unconscious processes.

Older people who report subjective cognitive decline are four times more likely to progress to dementia, and then these people are twice as likely to develop dementia when others substantiate their memory loss. Our social world reinforces these negative expectations. One unexpected observation is that subjective memory decline only predicts dementia if this self-evaluation causes concern. The social pathology of dementia is truly social and involves people around us. A "consensus trance" further promotes the self-evaluation, when other people-through stereotypes, expectations, and interactions-confirm these negative expectations. When older adults are exposed to negative stereotypes about age-related cognitive decline, their memory performance decreases. To complement this, others are more likely to judge you with dementia if they are exposed to the stereotype as well. Physicians that read articles revealing that older adults with memory issues are likely to have dementia, were more likely to diagnose their older clients with memory problems as having dementia $(70 \%)$ rather than when they did not read about the stereotype $(14 \%)$. The social pathology of dementia can play a key role in tipping the scales from temporary memory lapses to progressive dementia. This explains why longer-lived people that live free from dementia, live in communities of similarly older people (Blue Zones) where such negative stereotypes do not 
exist. Many other perceptual biases (some 230 such biases are documented) that may be applied, make our subjective negative evaluation come true. We become psychologically apathetic, not concerned so much with the world around as with focusing on the immediacy of our situation. We can see all these developments because apathy and depression correlate closely with dementia and they are indicative of a perceptual change. These emotions show that a radical perceptual change has occurred, a transformation that alters how we see the world. All of this happens in our unconscious, unbeknownst to us.

Like a house of cards, the edifice of social learning slowly unhinges and then dismantles as we come to rely on established patterns of behavior, while disregarding novelty. This slow process takes decades to express as dementia. Dementia just does not appear suddenly but incrementally. But when memory atrophies, we lose retrieval of memories that shape self-consciousness, selfknowledge, and self-image. Our lack of access to these memories not only leads to a diminished sense of self and identity, but also slows down acquisition of new knowledge, in general, as this loss of self-importance reduces our motivation to learn. Apathy, shadowed by depression, further reduces the motivation to learn. Activities that involve novelty-seeking — such as sharing, exchanging of ideas, and being social, all known to delay/prevent dementia - are avoided. In the same way that placebos change our biology and outcomes, nocebos and negative perceptual biases similarly bring about negative physical and biological changes. Social dementia promotes negative biological changes as much as biological changes promote social dementia.

Similar to false memories, social dementia follows a set pattern of validation. Dementia becomes promoted by how we feel, our emotions, in this case apathy, depression and the lack of interest in learning about the world around us: that is the social pathology of dementia. The remedy is to behave as when you were younger. That constant search for novelty, sharing experiences, learning new skills, exchanging ideas, and being social. Social dementia allows us to address at least one aspect of the many causes of dementia.

\section{List of all these Attacks}

a. Degenerative causes: Familial Alzheimer's disease; Pure hippocampal sclerosis; frontotemporal lobar degeneration; primary progressive (non-fluent) aphasia; Semantic dementia; Progressive supranuclear palsy (Steele-Richardson-Olszewsky syndrome); Corticobasal degeneration; Multiple system atrophy (Shy-Drager syndrome); Amyotrophic lateral sclerosis/ motor neuron disease (Lou Gehrig's disease); Huntington's disease; Ataxias (spinocerebellar ataxias, Friedreich's ataxia); Polycystic lipomembranous osteodysplasia with sclerosing leukoencephalopathy-Nasu-Hakola disease; Wilson disease; neuronal ceroid lipofuscinoses-Kufs disease; Gaucher disease (2 and 3); Fragile X syndrome; Fabry disease; Limbic encephalitis (LATE); Niemann-Pick disease Type C; and Spinocerebellar ataxia.

b. Vascular causes: Multi-infarct dementia; Single-infarct (post-stroke) dementia; Subcortical dementia; Cerebral autosomal dominant arteriopathy with subcortical infarcts and leukoencephalopathy-CADASIL; Binswanger's disease; Cerebral amyloid angiopathy; Creutzfeldt-Jakob diseasesporadic/iatrogenic/variant/familial; Fatal familial insomnia; and Gerstmann-Straussler-Scheinker disease.

c. Parasitic infections: Lyme dementia; Cerebral toxocariasis; and McLeod syndrome Neurocysticerosis.

d. Viral infections: herpes simplex virus type 1 and 2; Epstein-Barr virus; Viral meningitis; HIV-related dementia-AIDS dementia complex; Progressive multifocal Leukoencephalopathy; Subacute sclerosing panencephalitis; herpes virus types 6/7; cytomegalovirus; and varicella-zoster virus.

e. Bacterial infections: Tuberculous meningitis; Meningococcal meningitis; Whipple's disease; and Neurosyphilis.

f. Fungal infections: Cryptococcal meningitis.

\section{Acknowledgement}

None.

\section{Conflict of Interest}

No conflict of interest.

\section{References}

1. Macchi G, Brahe C, Pomponi M (1997) Alois Alzheimer and Gaetano Perusini: should man divide what fate united? Behavioural neurology 10(4): 105-108.

2. Garrett MD (2016) Politics of Anguish: How Alzheimer's disease became the malady of the 21st century. Kindle. USA.

3. Katzman R (1976) The prevalence and malignancy of Alzheimer disease: a major killer. Archives of neurology 33(4): 217-218.

4. Garrett MD, Valle R (2016) A Century of Confusion in Researching Alzheimer's Disease. Dementia: The International Journal of Healthcare 2(2): 13-22.

5. Jack CR, Albert MS, Knopman DS, McKhann GM, Sperling RA, et al. (2011) Introduction to the recommendations from the National Institute on Aging-Alzheimer's Association workgroups on diagnostic guidelines for Alzheimer's disease. Alzheimer's dementia 7(3): 257-262.

6. Jack CR, Bennett DA, Blennow K, Carrillo MC, Dunn B, et al. (2018) NIAAA research framework: toward a biological definition of Alzheimer's disease. Alzheimer's Dementia 14(4): 535-562.

7. Selkoe DJ (2001) Alzheimer's disease: genes, proteins, and therapy Physiological reviews.

8. Crystal HA, Dickson D, Davies P, Masur D, Grober E, et al. (2000) The relative frequency of "dementia of unknown etiology" increases with age and is nearly 50 percent in nonagenarians. Arch Neurol 57(5): 713-719. 
9. Polvikoski T, Sulkava R, Myllykangas L, Notkola IL, Niinisto L, et al (2001) Prevalence of Alzheimer's disease in very elderly people: a prospective neuropathological study. Neurology 56(12): 1690-1696.

10. Katzman R, Terry RD, DeTeresa R, Brown T, Davies P, Fuld P, et al (1988) Clinical, pathological, and neurochemical changes in dementia: a subgroup with preserved mental status and numerous neocortical plaques. Ann Neurol 23(2): 138-144.

a. Tomlinson BE, Blessed G Roth M (1970) Observations on the brains of demented old people. Journal of the neurological sciences 11(3): 205242.

b. Dickson DW (1997) Neuropathological diagnosis of Alzheimer's disease: a perspective from longitudinal clinicopathological studies. Neurobiology of aging 18(4): S21-S26.

c. Snowdon DA, Greiner LH, Mortimer JA, Riley KP, Greiner PA, et al. (1997) Brain infarction and the clinical expression of Alzheimer disease: the Nun Study. Jama 277(10): 813-817.

11. Knopman D (2003) Pharmacotherapy for Alzheimer's disease: 2002. Clinical neuropharmacology, 26(2): 93-101.

12. Price JL, Morris JC (1999) Tangles and plaques in nondemented aging and "preclinical" Alzheimer's disease. Annals of Neurology: Official Journal of the American Neurological Association and the Child Neurology Society 45(3): 358-368

13. Davis DG, Schmitt FA, Wekstein DR, Markesbery WR (1999) Alzheimer neuropathologic alterations in aged cognitively normal subjects. Journal of neuropathology and experimental neurology 58(4): 376-388.

14. Savva GM, Wharton SB, Ince PG, Forster G, Matthews FE, et al. (2009) Age, neuropathology, and dementia. New England Journal of Medicine 360(22): 2302-2309.

15. Garrett MD (2015) Politics of Anguish: How Alzheimer's disease became the malady of the 21st century. Kindle. USA

16. Garrett MD (2020) Multiple Causes of Dementia as Engineered Senescence. European Journal of Medical and Health Sciences 2(2).

17. Goldgaber, D, Schwarzman, A. I, Bhasin, R, Gregori, L, Schmechel, D, Saunders, A. M, ... Strittmatter, W. J. (1993) Sequestration of Amyloid $\beta$ Peptide a. Annals of the New York Academy of Sciences, 695(1): 139143.

18. Dror IE, Schmitz-Williams IC, Smith W (2005) Older adults use mental representations that reduce cognitive load: mental rotation utilizes holistic representations and processing. Experimental aging research 31(4): 409-420.

19. Blanchard-Fields F, Mienaltowski A, Seay RB (2007) Age differences in everyday problem-solving effectiveness: Older adults select more effective strategies for interpersonal problems. The Journals of Gerontology Series B: Psychological Sciences and Social Sciences 62(1): P61-P64.

20. Giray EF, Altkin WM, Vaught GM, Roodin PA (1976) The incidence of eidetic imagery as a function of age. Child development: 1207-1210.

21. Gray CR, Gummerman K (1975) The enigmatic eidetic image: a critical examination of methods, data, and theories. Psychological bulletin 82(3): 383 .

22. Siipola EM, Hayden SD (1965) Exploring eidetic imagery among the retarded. Perceptual and Motor Skills 21(1): 275-286.

23. Maltz M, Shinar D (1999) Eye movements of younger and older drivers. Human factors 41(1): 15-25.

24. Maguire EA, Woollett K, Spiers HJ (2006) London taxi drivers and bus drivers: a structural MRI and neuropsychological analysis. Hippocampus 16(12): 1091-1101.

25. Glenberg AM (1997) What memory is for. Behavioral and brain sciences 20(1): 1-19.

26. Wallich P (1996) Senile words. Scientific American 274(6): 26-27.
27. Garrett MD (2021) Social Dementia: The role of memory. Kindle, USA.

28. Conway M (1990) On bias in autobiographical recall: Retrospective adjustments following disconfirmed expectations. The Journal of Social Psychology 130(2): 183-189.

29. Simons DJ, Chabris CF (1999) Gorillas in our midst: Sustained inattentional blindness for dynamic events. perception 28(9): 10591074.

30. Merckelbach H, Dalsklev M, van Helvoort D, Boskovic I, Otgaar H (2018) Symptom self-reports are susceptible to misinformation. Psychology of Consciousness: Theory, Research, and Practice 5(4): 384.

31. Merckelbach H, Jelicic M, Jonker C (2012) Planting a misdiagnosis of Alzheimer's disease in a person's mind. Acta neuropsychiatrica 24(1): 60-62.

32. Ross M (1989) Relation of implicit theories to the construction of personal histories. Psychological Review 96(2): 341.

33. Koppara A, Wagner M, Lange C, Ernst A, Wiese B, et al. (2015) Cognitive performance before and after the onset of subjective cognitive decline in old age. Alzheimer's Dementia: Diagnosis, Assessment Disease Monitoring, 1(2): 194-205.

34. Mendonça MD, Alves L, Bugalho P (2016) From subjective cognitive complaints to dementia: who is at risk?: a systematic review. American Journal of Alzheimer's Disease Other Dementias® 31(2): 105-114.

35. Brigham DD, Toal PO (1990) The Use of Imagery in a Multimodal Psychoneuroimmunology Program for Cancer and Other Chronic Diseases. In Mental Imagery (pp. 193-198) Springer, Boston, MA.

36. Hess TM, Auman C, Colcombe SJ, Rahhal TA (2003) The impact of stereotype threat on age differences in memory performance. The Journals of Gerontology Series B: Psychological Sciences and Social Sciences 58(1): P3-P11.

37. Haslam C, Morton TA, Haslam SA, Varnes L, Graham R, et al. (2012) When the age is in, the wit is out": Age-related self-categorization and deficit expectations reduce performance on clinical tests used in dementia assessment. Psychology and aging 27(3): 778.

38. Buettner D (2012) The blue zones: 9 lessons for living longer from the people who've lived the longest. National Geographic Books.

39. Garrett MD (2021) Social Dementia: The role of memory. Kindle, USA.

40. Bock MA, Bahorik A, Brenowitz WD, Yaffe K (2020) Apathy and risk of probable incident dementia among community-dwelling older adults. Neurology.

41. Ownby RL, Crocco E, Acevedo A, John V, Loewenstein D (2006) Depression and risk for Alzheimer disease: Systematic review, metaanalysis, and metaregression analysis. Archives of General Psychiatry 63: 530-538.

42. Mowla A, Ashkani H, Ghanizadeh A, Dehbozorgi GR, Sabayan B, et al. (2008) Do memory complaints represent impaired memory performance in patients with major depressive disorder? Depression and anxiety 25(10): E92-E96.

43. El Haj M, Antoine P, Nandrino JL, Kapogiannis D (2015) Autobiographical memory decline in Alzheimer's disease, a theoretical and clinical overview. Ageing research reviews 23: 183-192.

44. Amanzio M, Geminiani G, Leotta D, Cappa S. (2008) Metaphor comprehension in Alzheimer's disease: Novelty matters. Brain and language, 107(1): 1-10.

45. Stern C, Munn Z (2010) Cognitive leisure activities and their role in preventing dementia: a systematic review. International Journal of Evidence-Based Healthcare, 8(1): 2-17.

46. Enck P, Benedetti F, Schedlowski M (2008) New insights into the placebo and nocebo responses. Neuron 59: 195-206

47. Benedetti F, Shaibani A (2018) Nocebo effects: more investigation is needed.

48. Loftus E (2020) The fiction of memory. 